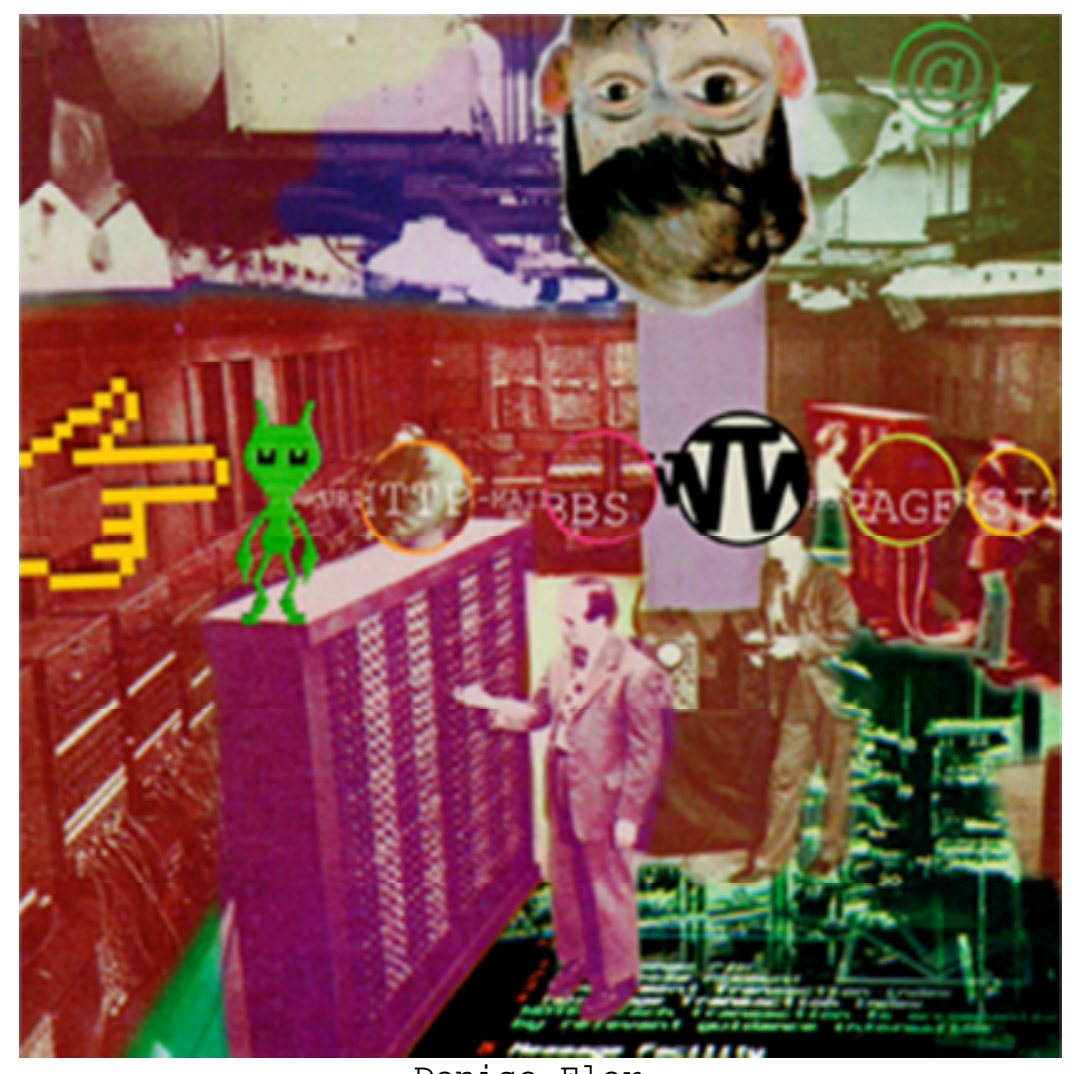

Denise Eler

As práticas museológicas emergentes na Internet e as tecnologias que as viabilizam

\title{
Denise Eler
}

Mestre em Educação Tecnológica, Especialista em Gestão Estratégica da Informação e professora de design gráfico da UEMG e da Universidade Fumec.

\section{Resumo}

Historicamente, os museus têm sido flexíveis na adoção de posturas e configurações favoráveis ao desenvolvimento social e humano, refletindo os contextos socioculturais em que estão inseridos. Este artigo lista e descreve algumas práticas museológicas emergentes, bem como as tecnologias que as viabilizam.

Palavras-chave: cibercultura, museus, Web 2.0, Web Semântica. 
Na década de 1980, os computadores pessoais despontavam como uma tecnologia que revolucionaria o modo de o ser humano lidar com a informação. Se em um primeiro momento, o interesse dos museus pela tecnologia deu-se pelas possibilidades de preservação e recuperação documental, logo viria sua exploração como suporte para os simulacros do acervo, passíveis de manipulação pelo público. Na década seguinte, o advento da web representava, para muitos, uma oportunidade de ampliar o número de visitantes presenciais. As tecnologias da web desenvolveram-se substancialmente, bem como a cultura tecnológica em geral, levando à consolidação da Internet como uma nova mídia capaz de deslocar, para si, públicos da TV e dos jornais impressos, para citar apenas duas das mais tradicionais fontes de informação e entretenimento contemporâneos. Embora a questão tecnológica não esclareça isoladamente 0 fenômeno das diversas formas de uso e apropriação da Internet pelos museus, seu papel no processo de desenvolvimento museológico não é secundário.

Sumption(1), ao analisar a produção intelectual de uma década da Conferência Museum and Web, revela:

\begin{abstract}
temo que tenhamos criado uma divisão - uma separação dos domínios físico e online - que apenas agora estamos começando a transpor. Como veremos, isto não se deve a qualquer falta de interesse ou desejo de reunir o museu virtual e o museu físico. Na verdade, estávamos esperando pela maturação de um número de tecnologias "affordance" (2) • (tradução nossa)
\end{abstract}

O termo "affordance" foi originalmente cunhado por James Gibson(3), para definir a relação estabelecida entre o objeto e seu usuário em termos de possibilidades de ação. Gibson procurava compreender como informações disponíveis para o agente eram efetivamente percebidas e contribuíam para a regulação do comportamento(4). A partir de 1988, o termo foi apropriado por Donald Norman e aplicado ao designde produto e de interfaces digitais(5) referindo-se à forma com que os artefatos sugerem interações possíveis com os usuários. Com efeito, nos últimos cinco anos, uma série de tecnologias tem facilitado o uso e a apropriação da webpelos usuários, caracterizando suas segunda e terceira gerações de serviços, as chamadas Web 2.0. e 3.0.

\title{
As tecnologias da web de segunda e terceira gerações
}

O termo Web 2.0 foi usado pela primeira vez em 2004, por Tim O'Reilly, na Conferência O'Reilly Media, nos EUA, para identificar uma mudança cultural nas formas de fazer negócio e se comunicar na Internet. O nome não se referia a uma atualização tecnológica especificamente, como a notação 2.0 sugere, mas a novas formas de uso da web, tanto por desenvolvedores de softwares quanto por usuários finais. 
Dentre as principais características da segunda geração está o uso da web como plataforma permitindo que muitas tarefas, como - uso de uma planilha ou de um processador de textos, sejam realizadas sem que o usuário tenha de ter um softwareespecífico instalado em seu computador. A Google é uma das empresas ícones da filosofia Web 2.0, em oposição à Microsoft. Enquanto a primeira está focada na oferta de serviços online, o negócio da segunda é o licenciamento desoftwares (embora essa posição já comece a ser revista com o lançamento do Windows Live). Outro conceito importante para entender a nova lógica da Internet é o que O’Reilly (6) define como "arquitetura de participação". Antes passivos consumidores de serviços, os usuários dos sítios 2.0 agregam valor ao negócio participando ativamente na geração, no compartilhamento e na divulgação do conteúdo. Para que isso seja possivel, os desenvolvedores criam estratégias e estruturas que estimulam a participação dos usuários, promovendo-os a co-autores de conteúdo e a co-desenvolvedores do sistema. Nesse modelo, os usuários são vistos como colaboradores de um serviço que se aperfeiçoa na medida em que é usado. São exemplos dessa filosofia a Amazon.com, a Wikipedia e osblogs. Em ambos os casos, para O'Reilly(7), a questão central da Web 2.0 são os dados gerados pelos usuários e quem os controla ou dá o melhor acesso a uma classe de dados, como faz o Ebay, por exemplo, uma autoridade no mercado de leilões, ou o Submarino, na venda de produtos pela Internet brasileira. Construir aplicações que tirem proveito dos efeitos do trabalho coletivo é o objetivo maior de empresas e instituições trabalhando na filosofia Web 2.0. As principais práticas e tecnologias que suportam este modelo emergente de apropriação do ambiente web serão descritas a seguir (v. gráfico 01). 


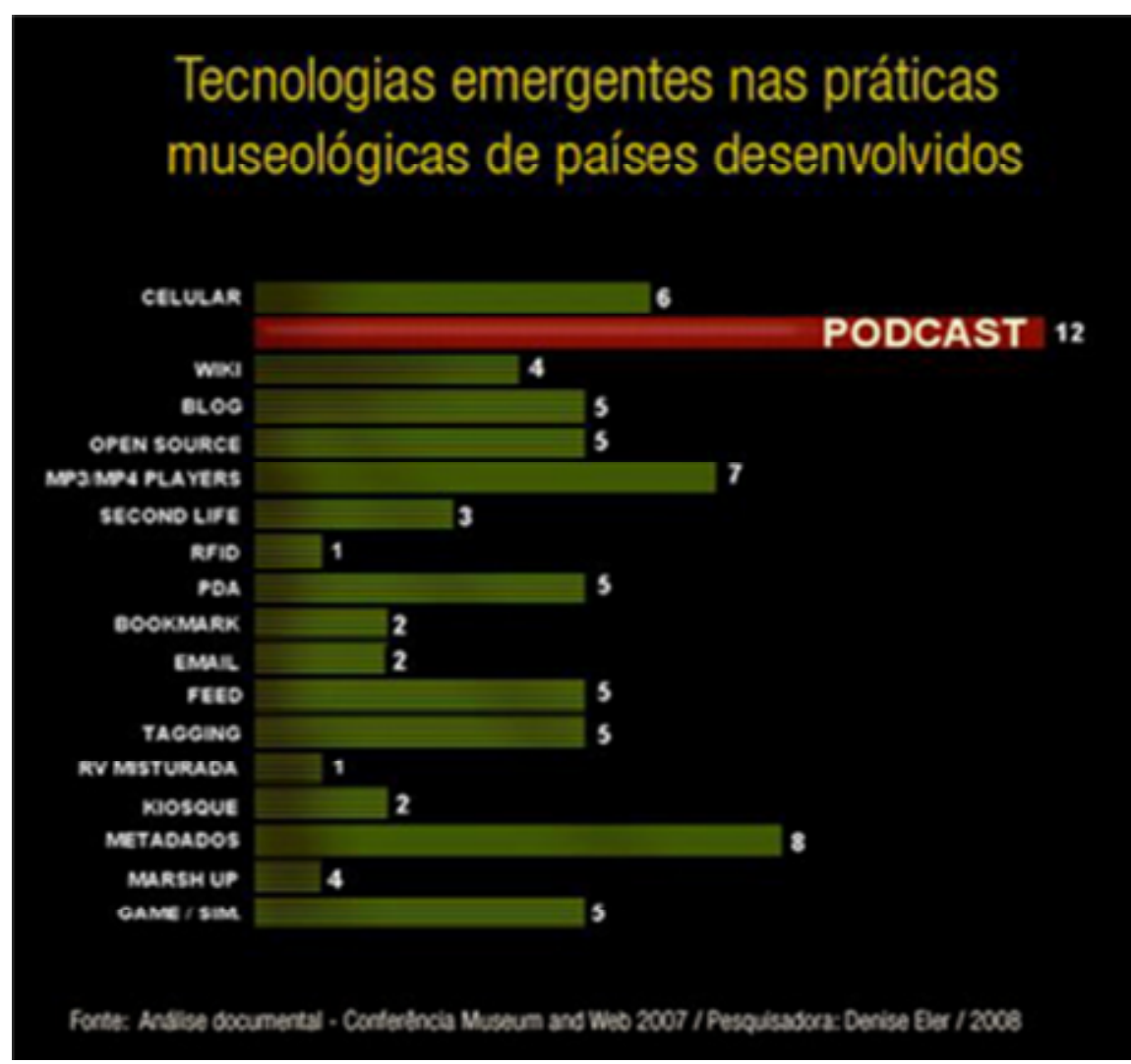

Gráfico 01 - Tecnologias emergentes em museus.

Fonte: Dados da pesquisa.

Tagging (etiquetagem): São sistemas que habilitam usuários a acrescentar palavras-chave nos recursos digitais da web sem 0 uso de vocabulários controlados(8). Essa prática deu origem ao que alguns(9) acreditam ser um novo paradigma de classificação de conteúdo, denominado folksonomia, em analogia à forma clássica de classificação de recursos conhecida por taxonomia. Segundo Peacock(10), a etiquetagem de páginas web (Web Page Tagging) emerge como um novo método de rastreamento do comportamento de usuários.

Wiki: Trata-se de um software que permite a criação e a edição livre do conteúdo de um sítio, em qualquer navegador. A prática encoraja o uso democrático da web por dispensar qualquer conhecimento técnico dos usuários. Um dos wikis mais conhecido é a Wikipedia, uma enciclopédia online escrita por usuários-colaboradores.

Blog: Sítio cujo conteúdo é apresentado cronologicamente e atualizado freqüentemente. Permite que um ou mais autores, definidos por um administrador, postem conteúdos passíveis de comentários de terceiros. Esses, por sua vez, podem acrescentar links para outros nós da rede. Como os wikis, o serviço não demanda conhecimento técnico dos usuários. 
Considerado o software social mais fácil de ser iniciado, tem sido utilizado pelos museus de duas formas: como acesso público aos seus bastidores através de postagens dos curadores e do pessoal que trabalha nas instituições ou como comunidade aberta à publicação de qualquer usuário registrado. Segundo Spadaccini e Sebastian(11), essa plataforma de comunicação emergente tem catalisado a formação de uma comunidade museal na Internet. Os blogs de maior acesso são o que incentivam a participação de seus usuários, substituindo o modelo broadcast de comunicação por um modo conversacional, incentivando o diálogo no lugar de disseminar a informação(12). Para esses autores,

como muitas campanhas de marketing viral têm descoberto, blogstambém apresentam um bom custo-benefício para "jogar" com os sistemas de busca, aumentando rapidamente seu PageRank(13) e, por conseqüência, sua encontrabilidade. Além disso, quanto mais páginas, categorias e palavras-chaves são geradas pelo blog, maior o conteúdo para ser indexado, resultando em cada vez mais visitantes extras vindos dos sistemas de busca. Ter uma presença na bloguesfera e no mundo mais amplo da Web 2.0 pode ajudar a garantir visibilidade no "tradicional" mundo Web 1.0.(14) (tradução nossa).

Dentre outras vantagens dos blogs de museus, estão a possibilidade de atualização dinâmica de conteúdo, sem custo adicional para a instituição, a quebra da estrutura autoritária de comunicação predominante, a possibilidade de o conteúdo das postagens ser usado como indicadores de interesse, a valorizção da preferência e do conhecimento dos usuários sobre determinado assunto(15), a possibilidade de fortalecer a conexão com o público jovem e de integrar as duas instâncias do museu(16). Os autores advertem, no entanto, para a necessidade de divulgar o blog na Internet, em sítios afins como o Flickr (site de compartilhametno de imagens) e mostram a importância da persistência para que uma comunidade participativa se forme.

Mash-ups (misturas): São aplicações híbridas, formadas a partir de dois ou mais aplicativos da web, e reunidas em um só lugar. O exemplo mais popular tem sido o uso do Google Maps em sítios de negócios imobiliários, oferecendo maiores detalhes dos imóveis disponíveis.

Podcasting ou webcasting: nome dado ao sistema de distribuição de áudio via Internet, no formato de arquivos digitais de áudio e/ou vídeo, para uso em computadores pessoais ou tocadores portáteis, como Mp3 players. A grande vantagem dos podcasts é sua associação aos feeds (download automático). Uma vez assinado o feed de um podcast, o usuário passa a receber os arquivos subseqüentes sem nenhum esforço adicional, além do de especificar o agregador de sua preferência. Da mesma forma, o usuário tem a oportunidade de produzir seu 
próprio conteúdo e disponibilizá-lo na Internet para uso de interessados, sem custo e necessidade de conhecimentos técnicos avançados.

Feeds, Atom e RSS: Atom e RSS, abreviação de "Really Simple Syndication" (distribuição realmente simples) são tipos defeeds, ou seja, são formas pelas quais os usuários podem se manter atualizados sobre o conteúdo de um ou mais sítios sem ter que acessá-los diretamente. Uma vez assinado um conteúdo, - usuário passa a receber automaticamente as novidades em seu agregador de feeds. O agregador reúne todas as assinaturas em uma única interface, podendo ser instalado no computador pessoal ou simplesmente acessado na web. O uso dessa tecnologia vem alterando o comportamento dos usuários, uma vez que não é mais preciso visitar um determinado sítio, mas apenas o agregador e, ao mesmo tempo, tem ampliado as formas de acesso e distribuição dos conteúdos dos sítios. O fenômeno tem sido denominado Web Syndication e, para alguns, é um dos melhores exemplos da aplicação da Web Semântica (Web 3.0) fora do círculo acadêmico(17).

Segundo Berners-Lee(18), a Web Semântica será uma extensão da web atual, porém apresentará uma estrutura que possibilitará às máquinas "compreender" e gerenciar os conteúdos armazenados independentemente da forma em que esses se apresentem. A W3C, órgão que regulamenta a web, está trabalhando no desenvolvimento de tecnologias para a representação estrutural e semântica (metadados) dos recursos dispostos na rede a fim de que as máquinas possam inferir novos conhecimentos sobre dados atualmente desconexos.

O que a Web Semântica oferece é um modelo mais consistente e ferramentas para a definição e uso de relações qualificadas entre os dados que estão na web. (...) Várias das demonstrações e aplicações típicas da Web 2.0 emergem do uso de ferramentas da Web Semântica combinadas com AJAX dentre outras(19) (tradução nossa).

Como se pode notar, a Web 2.0 é antes uma questão conceitual que se realiza graças à formação de uma massa crítica de usuários da rede e a diversas tecnologias, muitas das quais existentes desde a origem da própria web. A Web 2.0 pode ser entendida então como um marco histórico da Internet, onde se dá a apropriação do ambiente online pelos usuários, por meio da proliferação de uma série de tecnologias persuasivas orientadas para a boa usabilidade e focadas na interação social. Se o foco da Web 2.0 é a interação social em escala, a Web 3.0 será a geração da interação entre dados.

No entanto, beneficiar-se da Web 2.0 pressupõe compreender e aceitar valores que lhe são inerentes como o compartilhamento de autoridade. A mudança de paradigma em curso exige que os museus desloquem-se da postura de disseminadores de informação 
para o papel de agências de diálogo(20). Esse processo exige uma mudança de cultura nas instituições, o que pode ser uma barreira para a transformação da forma como os museus brasileiros têm explorado a Internet.

Embora incipiente, a filosofia Web 3.0 já pode ser notada em sítios que levam em consideração a estruturação semântica da informação e a inter-operabilidade, nome dado à habilidade de troca de serviços e dados entre sistemas distintos. Esses projetos prevêem a reutilização da informação em várias mídias e formatos, realizando a visão do museu ubíqüo, onde o que é produzido no domínio físico pode ser reutilizado na Internet e vice-versa, reduzindo custos e facilitando a gestão da informação. A vocação para a conectividade inerente às tecnologias digitais tem catalisado a integração dos domínios físico e virtual dos museus que as adotam, embora essa relação não seja determinista. A viabilização dessa rede potencial é possível graças ao incentivo do uso de dispositivos familiares ao público, como aparelhos celulares, tocadores de MP 3 e MP4, e PDAs (ou handhelds - computadores de mão). Dessa forma, a experiência museal pode ser prolongada uma vez que vídeos, áudios, imagens e textos podem ser armazenados, acessados e compartilhados posteriormente. No entanto, a obsolescência dos aparelhos PDAs pode ser uma restrição ao uso da tecnologia(21), que, como os demais dispositivos móveis, apresenta outras desvantagens, como a resistência do público à mudança cultural (uso dos aparelhos no ambiente museal), a redução da interação social e o desvio da atenção do visitante. Em centros de ciências onde as atividades são guiadas pela filosofia handson (mãos na massa) forçar o visitante a carregar um aparelho pode parecer uma incoerência, razão pela qual se tem sugerido o uso de handhelds apenas em exposições temporárias.

Bookmarking e RFID: Um dos usos dos handhelds tem sido na prática o do bookmarking - nome dado a uma série de tecnologias que permite o acesso de uma informação selecionada pelo visitante para uso posterior, seja por meio do armazenamento em uma página específica do sítio, em um aparelho de MP3, ou pelo recebimento por e-mail. FilippiniFantoni e Bowen(22) acreditam que em uma cultura de "informação sob demanda", o bookmarking tem 0 potencial de tornar-se a principal ponte entre as visitas "real" e "virtual" ao museu, porém, ao analisarem as estatísticas de uso do serviço em diversos museus europeus, concluíram que há diferentes razões impedindo que as expectativas sejam alcançadas. Dentre elas, existem falta de interesse e de tempo dos visitantes para acessar as informações posteriormente, desconhecimento do serviço no museu físico, falta de visibilidade e clareza de como usar o serviço no museu virtual. A pesquisa indicou que o serviço tem um apelo maior para públicos específicos, com interesses definidos, como no caso 
da comunidade escolar. Por ser uma prática inovadora, é necessário que o público seja instruído sobre a tecnologia e seus benefícios e que seja igualmente fácil encontrar o conteúdo selecionado no sítio do museu.

Uma segunda forma de oferecer o serviço de bookmarking aos visitantes tem sido viabilizada pela tecnologia RFID (Identificação por Radiofreqüência), que usa ondas de rádio para identificar objetos automaticamente. Nos museus, o sistema é usado para identificar visitantes individuais que portam uma etiqueta RFID no pulso e a utilizam para marcar as informações disponíveis nos quiosques e consultá-las posteriormente. Uma vez informado $O$ código RFID recebido durante a visita, o usuário pode usufruir de um sítio customizado segundo seus interesses pessoais.

A distribuição automática de conteúdo (RSS) está inserida na filosofia de acesso ao conteúdo do museu fora do museu, porém, associada ao podcasting, permite que os arquivos de áudio e vídeo produzidos pelos museus (visitas guiadas) ou por usuários do sítio possam ser usados durante a visita, em seus próprios aparelhos. Além da questão econômica para ambas as partes, os museus têm incentivado essa prática para aproveitar - conhecimento que cada visitante tem de seu próprio aparelho, poupando-o do trabalho de aprender a operar um artefato que lhe é estranho. Além disso, ao publicar podcasts em sítios como o itunes, o museu está ampliando sua presença online, alcançando um público muitas vezes não freqüentador do museu ou de seu sítio. Os inconvenientes dos podcasts(23) estão em seu formato linear e no pré-requisito de que o visitante baixe o áudio em seu aparelho, antecipadamente à ida ao museu.

Encontrar modos de usar as tecnologias do cotidiano que as pessoas carregam consigo quando estão transitando - tais como celulares, PDAs, ipods e câmeras digitais - é uma interessante oportunidade para o museu fazer conexões com ambientes tecnológicos e literacias que os visitantes trazem consigo.(24) (tradução nossa)

Finalmente, para os que se preocupam ainda com a questão da tatilidade, da aura perdida do artefato no ambiente virtual, as interfaces hápticas parecem apontar um caminho. O Museu da pura forma, na Itália, tem realizado experiências com interfaces hápticas que permitem ao usuário tocar e sentir as representações virtuais dos artefatos do museu. Por meio de um pluggin, usuários do sítio podem acessar uma versão simplificada da exibição instalada no museu físico. Embora a tecnologia já exista há mais de uma década, só agora, com a redução dos custos e o avanço de alguns softwares ehardwares, tem sido possível explorar as oportunidades que o senso tátil abre no campo da interação. 
Neste artigo, pudemos perceber que as práticas museológicas emergentes na Internet caminham para a flexibilização da autoridade, rumo à adoção de uma postura dialógica por parte dos museus, na busca de uma maior interação com seus públicos. Independentemente da tipologia a que pertençam, percebe-se um movimento de apropriação do ambiente onlinecomo uma unidade identitária complementar ao ambiente físico. Nesse sentido, a prática do tagging merece particular atenção, na medida em que o conhecimento leigo pode ser explicitado e compartilhado com os museus, ampliando as fontes de informação dessas instituições e, paralelamente, revelando a percepção que o público tem de seu acervo.

\section{Abstract}

Historically, museums have been flexible in adopting practices and settings which are advantageous to social and human development. This article lists and describes both some emergent museum practices and the technologies that make them possible.

Key-words: cyberculture, museums, Web 2.0, Semantic Web.

\section{Notas}

[1] SUMPTATION, 2007.

[2] SUMPTION, 2007.

[3] GIBSON, 1977.

[4] GREENO, 1994.p. 338.

[5] NORMAN, 1988.

[6] O'REILLY, 2006.

[7] O'REILLY, 2007.

[8] MARLOW, 2006.

[9] VALONGUEIRO, apud CATARINO, 2007.

[10] PEACOCK, 2007.

[11] PADACCINI et al., 2007.

[12] GATES, 2007.

[13] GOOGLE, 2007.

[14] SPADACCINI, SEBASTIAN, 2007.

[15] WITSCHEY et al., 2006.

[16] GATES, 2007.

[17] DOWNES, 2005.

[18] BERNERS-LEE, 2001.

[19] W3C, 2007.

[20] GATES, 2007.

[21] WITSCHEY et al., 2006.

[22] FILIPPINI-FANTONI et al., 2007.

[23] WITSCHEY et al., 2006.

[24] MACDONALD et al., 2007. 


\section{Referências bibliográficas}

BERNERS-LEE, T., HENDLER, J., LASSILA, O. The Semantic Web. Scientific American, Mai/2001, p. 29-37. Disponível em http://www.sciam.com/article.cfm?id=the-semantic-web. Acesso em: $05 / 04 / 02008$.

CATARINO, M. A., BAPTISTA, A. A. Folksonomia: um novo conceito para a organização dos recursos digitais na Web. DataGramaZero,v.8 n.3, jun/07, artigo 04 . Disponível em: http://www.dgz.org.br/jun07/Art_04.html. Acesso em $05 / 010 / 2007$.

DOWNES, S. Semantic networks and social networks. The Learning Organization; v. 12 Issue, 5. 2005. Disponível em: http://www.downes.ca/cgibin/page.cgi?post=31624. Acesso em: 03/01/2007.

GATES, J. Case Study: New World Blogging within a Traditional Museum Setting . In:Museums and the Web 2007, 2007, San Francisco, California. Museums and the Web 2007: Proceedings. Toronto, Canadá : Archives \& Museum http://www.archimuse.com/mw2007/papers/gates/gates.html._Acesso em: $10 / 04 / 2007$.

GREENO, J.G. Gibson's affordances. Psychological Review. v. $101(2) 1994$, p. 336-342. Disponível http://ecologylab.cs.tamu.edu/courses/physicalInterfaces/ hostedMaterials/gibsonAffordances.pdf>. Acesso em 18/07/08.

GIBSON, J. J. The theory of affordances. In: R. Shaw \& J. Bransford (Eds.), Perceiving, acting, and knowing: toward an ecologicalpsychology, 1977, p. 67-82. Hillsdale, NJ: Erlbaum.

MACDONALD, D. et al. Science Mobilized: Bringing Up-To-The-Minute Headlines Into The Museum and Back Out Again: "The Times Square of Science and Technology". In: Museums and the Web 2007. San Francisco, California. Museums and the Web 2007: Proceedings. Toronto, Canadá: Archives \& Museum Informatics. Toronto, Canadá : Archives \& Museum Informatics, 2007. Disponível em: http://www.archimuse.com/mw2007/papers/macdonald/macdonald.html. Acesso em: $13 / 05 / 2007$.

MARLOW, C., NAAMAN, M., BOYD, D., DAVIS, M. Position Paper, Tagging , Taxonomy, Flickr, Article, ToRead. In: wWw 2006 Iinternational World Wide Web Conference, 15, 2006, Edinburgo Scotland. Papers. Disponível em: http://wWw.danah.org/papers/WWW2006.pdf. Acesso em: 14/11/2006.

NORMAN, D. A. Affordances, Conventions and Design. In: Interactions, 6 (3), 1999, p. 38-4141 Disponível em: http://www.jnd.org/dn.mss/affordance_conv.html. Acesso em: 10 /05/2008.

O'REILLY, T. Web 2.0 Is About Controlling Data. 13/04/2007. Revista Wired. Tech Bizz: People. Disponível em: http://www.wired.com/techbiz/people/news/2007/04/timoreilly_0413. Acesso em $20 / 09 / 2007$.

.Web 2.0 Compact Definition: Trying Again 10/12/2006. Disponível em: http://radar.oreilly.com/2006/12/web-20-compact-definitiontryi.html> Acessado em: 18/08/2008.

The Architecture of Participation. jun/04. Disponivel em: http://www.oreillynet.com/pub/a/oreilly/tim/articles/architecture_of_partic 
ipation.html. Acesso em: 11/03/2007.

PEACOCK, D. e BROWNBILL, J. Audiences, Visitors, Users: Reconceptualising Users of Museum On-line Content and Services. In: Museums and the Web 2007, San Francisco, California. Museums and the Web 2007: Proceedings. Toronto: Archives \& Museum Informatics. Toronto, Canadá : Archives \& Museum Informatics, 2007. Disponível em: http://www.archimuse.com/mw2007/papers/peacock/peacock.html. Acesso em $13 / 05 / 2007$.

SUMPTION, K. Search Of The Ubiquitous Museum: Reflections of Ten Years of Museums And The Web. In:Museums and the Web 2006, 2006, Toronto: Archives \& Museum Informatics. Disponível em: http://www.archimuse.com/mw2006/papers/sumption/sumption.html. Acesso em $01 / 03 / 06$.

WITSCHEY, W. R. T.; et al. Museums in transition: emerging technologies as tools for free-choice learning. Informal Learning Review, The, n.81, Nov. /Dez. $2006 . \quad$ Disponível em: http://www.archimuse.com/mw2006/papers/semper/semper.html. Acesso em: $20 / 03 / 07$. 